\title{
Brain Natriuretic Peptide and Troponin T in Patients With Acute Pulmonary Embolism and Grade 3 Obesity: A Retrospective Analysis
}

Carolina Borz-Baba ${ }^{1}$, Mian Munir ${ }^{2}$, Dorothy Wakefield ${ }^{3}$, Richard Feinn ${ }^{4}$

1. Internal Medicine, Saint Mary's Hospital, Waterbury, USA 2. Internal Medicine, Saint Mary’s Hospital, Waterbury, USA 3. Statistics, Saint Francis Hospital \& Medical Center, Hartford, USA 4. Statistics, Frank H. Netter M.D. School of Medicine, North Haven, USA

Corresponding author: Carolina Borz-Baba, carolina.borzbaba@trinityhealthofne.org

\section{Abstract}

\section{Introduction}

The interpretation of brain natriuretic peptide (BNP) and Troponin $\mathrm{T}(\mathrm{TnT})$ in patients with obesity is very challenging. The applicability of these biomarkers as prognostic indicators of increased mortality in pulmonary embolism (PE) in patients with Grade 3 obesity has yet to be determined.

\section{Methods}

To investigate whether the combination of BNP and TnT may help to identify patients at low risk for shortterm mortality, we assessed 92 patients admitted with the diagnosis of PE and Grade 3 obesity. The study endpoint was all-cause mortality at 30 days.

\section{Results}

The negative predictive value (NPV) of these tests combined is $98.8 \%$; however, we were not able to detect a statistically significant difference between the patients who had a BNP $<100 \mathrm{pg} / \mathrm{mL}$ and TnT $<0.03 \mathrm{ng} / \mathrm{mL}$ and the other individuals who had either BNP $\geqslant 100 \mathrm{pg} / \mathrm{mL}$ or $\mathrm{TnT} \geqslant 0.03$ or both. The mortality rate was $5.43 \%$ within 30 days of the diagnosis. The logistic regression analysis using BNP and troponin as continuous variables identified BNP $(\mathrm{p}<0.005)$ as an independent predictor for 30 days mortality. Receiver operating characteristic (ROC) analysis determined that a BNP level of $684 \mathrm{pg} / \mathrm{mL}$ was the cutoff level to predict mortality in the population studied.

\section{Conclusions}

Our results support that BNP and TnT levels retain an excellent NPV among patients with PE and Grade 3 obesity. BNP testing could be an independent predictor of high-risk patients in this population. The low incidence of all-cause mortality in this study (5.43\%) is primarily explained by the more frequent use $(9.75 \%)$

Received 06/23/2020

Review began $06 / 30 / 2020$ Review ended 07/07/2020 Published 07/19/2020

\section{() Copyright 2020}

Borz-Baba et al. This is an open access article distributed under the terms of the Creative Commons Attribution License CC-BY 4.0., which permits unrestricted use, distribution, and reproduction in any medium, provided the original author and source are credited. of systemic or catheter-based thrombolysis associated with a lower rate of major bleeding compared to the general population.

Categories: Internal Medicine, Pulmonology

Keywords: biomarker, prognosis, pulmonary embolism, grade 3 overweight

\section{Introduction}

Pulmonary embolism (PE) is currently the third most common acute cardiovascular disease worldwide with a $10-30 \%$ estimated mortality within 30 days of diagnosis [1,2]. With an age-adjusted prevalence of $42.45 \%$, obesity has emerged amongst the common modifiable provoking factors for PE [3]. When employed in the appropriate clinical circumstances and in conjunction with imaging findings, the markers of myocardial injury (cardiac troponins, I or T) and right ventricular dysfunction (BNP) are considered essential in the risk stratification of patients with pulmonary embolism. The presence of lower BNP values in obese patients and of a linear increase in high sensitivity troponin T level in patients with a BMI $>35 \mathrm{~kg} / \mathrm{m}^{2}$ poses a challenge in the accurate interpretation of these biomarkers in patients with acute pulmonary embolism and Grade 3 obesity $\left(\mathrm{BMI} \geqslant 40 \mathrm{~kg} / \mathrm{m}^{2}\right)[4,5]$. The role of concomitant use of both cardiac markers in the prognosis of mortality among patients with obesity Grade 3 has not been studied yet.

\section{Materials And Methods Study objectives}

Clinical and biochemical data were selected via electronic medical record (EMR) chart review from all consecutive admissions with the diagnosis of acute pulmonary embolism and Grade 3 obesity between 2016 
and 2019 (July 2016-December 2019) from three hospitals in the region. We included patients with a concomitant diagnosis of congestive heart failure, chronic obstructive pulmonary disease (COPD), renal failure, malignancy, hemodynamic instability and patients who received thrombolysis. We retrospectively searched for all consecutive assays for cardiac-T and BNP of these subjects.

Biochemical assay: Samples were analyzed using different types of quantitative methods based on the institution's medical equipment. BNP was assessed by immunoenzymatic method, Beckman, or immunofluorescence method by TRIAGE. The cut-off value for normal BNP was $<100 \mathrm{pg} / \mathrm{mL}$. Troponin T (TnT) was analyzed by immunoenzymatic, Becker, or immunofluorescence method by TRIAGE. The cut-off for abnormal $\mathrm{TnT}$ was $\geqslant 0.03 \mathrm{ng} / \mathrm{mL}$.

To determine the predictive value of both BNP and troponin, the participants in the study were divided into four groups. Group 1 of subjects had a normal BNP (defined as $<100 \mathrm{pg} / \mathrm{mL}$ ) and normal TnT $(<0.03 \mathrm{ng} / \mathrm{mL}$ ), group 2 of subjects had high BNP $(\geqslant 100 \mathrm{pg} / \mathrm{mL})$ and normal TnT $(<0.03 \mathrm{ng} / \mathrm{mL})$, group 3 of patients had at least one abnormal TnT $(\geqslant 0.03 \mathrm{ng} / \mathrm{mL})$ and normal BNP $(<100 \mathrm{pg} / \mathrm{mL})$ and group 4 of subjects with high BNP $(\geqslant 100 \mathrm{pg} / \mathrm{mL})$ and at least one abnormal TnT $(\geqslant 0.03 \mathrm{ng} / \mathrm{mL})$. Radiological evidence of right ventricular dysfunction, defined by computed tomography pulmonary angiography (CTPA) (right ventricular diameter/left ventricular diameter ratio of $\geqslant 1$ in conjunction with septal bowing) was examined for the patients in group 1 . The imaging was reviewed independently by two radiologists. Hemodynamic instability was defined as systolic blood pressure (SBP) $<90 \mathrm{mmHg}$ for at least 15 minutes.

\section{Study endpoint}

The endpoint of the study was all-cause mortality within 30 days of diagnosis. The protocol of the study was approved by the IRB committee.

\section{Statistical analysis}

Data categorized by a normal distribution are represented as mean values followed by the standard deviation. For the categorical variables, we used Wald Chi-Square. Logistic regression was performed for the set of univariable predictors. The tests used included a two-sided analysis. Results were considered statistically relevant at $\mathrm{P}<0.05$. We used Statistical Analysis System software for the statistical calculations.

\section{Results \\ Demographics}

Acute pulmonary embolism was diagnosed in 130 patients with Grade 3 obesity. The diagnosis was based on clinical evidence and imaging data obtained by CTPA or ventilation-perfusion (V/Q) scan. Echocardiography was employed to determine if right ventricular dysfunction (RVD) was present in $90.7 \%$ of cases. Only 92 patients (70.7\%) had both BNP and at least one TnT assessed during hospitalization and were finally enrolled in the study.

The study included 68 (74\%) women and 24 (26\%) men aged: 55 +/- 14 SD with BMI $47+/-7$ SD. At least one of the following coexisting conditions was present in 44 patients (47.8\%): congestive heart failure (CHF), renal failure (RF), coronary artery disease (CAD), chronic obstructive pulmonary disease (COPD) and malignancy. Hemodynamic instability, defined as a systolic blood pressure of $<90$ for at least 15 minutes, was documented in 14/92 (15.2\%). Either systemic or catheter-based thrombolysis was administered in nine cases $(9.75 \%)$, and no patients underwent thrombectomy. None of the patients who received thrombolysis expired in the first 30 days. Death was recorded in five patients (5.43\%) included in the study; however, six patients (4.61\%), of the total number of 130 patients initially screened, died at 30 days. Three patients presented more than once with the diagnosis of acute pulmonary embolism, but none expired in the first 30 days.

The group characteristics based on the BNP and troponin levels are detailed in Table 1 . 


\section{Cureus}

\begin{tabular}{|c|c|c|c|c|}
\hline & $\begin{array}{l}\text { Group } 1 \text { BNP }<100 \\
\mathrm{pg} / \mathrm{mL}, \mathrm{TnT}<0.03 \mathrm{ng} / \mathrm{mL}\end{array}$ & $\begin{array}{l}\text { Group } 2 \text { BNP } \geq 100 \\
\mathrm{pg} / \mathrm{mL}, \mathrm{TnT}<0.03 \mathrm{ng} / \mathrm{mL}\end{array}$ & $\begin{array}{l}\text { Group } 3 \text { BNP }<100 \\
\mathrm{pg} / \mathrm{mL}, \mathrm{TnT} \geq 0.03 \mathrm{ng} / \mathrm{mL}\end{array}$ & $\begin{array}{l}\text { Group } 4 \mathrm{BNP} \geq 100 \mathrm{pg} / \mathrm{mL} \text {, } \\
\mathrm{TnT} \geq 0.03+\mathrm{ng} / \mathrm{mL}\end{array}$ \\
\hline $\begin{array}{l}\text { Number of } \\
\text { patients }\end{array}$ & 25 & 6 & 24 & 37 \\
\hline Age & $52+/-13$ & $58+/-15.5$ & $52.8+/-14$ & $57.7+/-13.3$ \\
\hline $\begin{array}{l}\text { Female } \\
\text { gender } \mathrm{n}(\%)\end{array}$ & $19(76)$ & $4(66)$ & $15(62.5)$ & $23(62)$ \\
\hline BMI & $45.7+/-5$ & $52.3+/-13$ & $47+/-5.8$ & $47.1+/-7.6$ \\
\hline $\begin{array}{l}\text { SBP < } 90 \\
\text { mmHg n (\%) }\end{array}$ & $0(0)$ & $2(33)$ & 1 (4) & $12(32)$ \\
\hline CHF n (\%) & $5(20)$ & $5(83)$ & $5(21)$ & $12(25.5)$ \\
\hline CAD n (\%) & $0(0)$ & 2 (33) & $1(4)$ & $6(16)$ \\
\hline COPD n (\%) & $3(12)$ & $0(0)$ & $3(12.5)$ & $6(16)$ \\
\hline $\begin{array}{l}\text { Renal failure } \\
\text { n (\%) }\end{array}$ & $3(12)$ & $2(33)$ & $8(33)$ & 14 (38) \\
\hline $\begin{array}{l}\text { Malignancy n } \\
\text { (\%) }\end{array}$ & $5(20)$ & 1 (17) & $3(12.5)$ & 2 (5) \\
\hline $\begin{array}{l}\text { All cause } \\
\text { mortality n } \\
\text { (\%) }\end{array}$ & 0 & 0 & $1(4)$ & 4 (11) \\
\hline
\end{tabular}

\section{TABLE 1: Characteristics of the patients by group}

BNP: Brain natriuretic peptide; TnT: Troponin T; BMI: Body mass index; SBP: Systolic blood pressure; CHF: Congestive heart failure; CAD: Coronary artery disease; COPD: Chronic obstructive pulmonary disease.

The negative predictive value of combined BNP $<100$ and $\mathrm{TnT}<0.03$ with a $95 \% \mathrm{CI}$ is $98.8 \%$. PPV of BNP $\geqslant$ 100 and $\operatorname{TnT} \geqslant 0.03$ is $10.8 \%$.

When comparing group 1 with the other groups, using either a BNP cutoff of $100 \mathrm{pg} / \mathrm{mL}$ (Figure 1) or 54 $\mathrm{pg} / \mathrm{mL}$ (Figure 2), no statistical difference was noted.

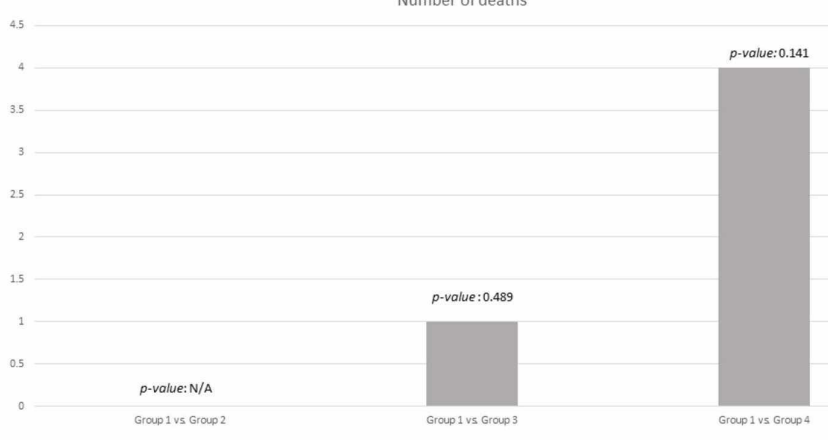

FIGURE 1: Primary endpoint between groups using a brain natriuretic peptide (BNP) cutoff of $100 \mathrm{pg} / \mathrm{mL}$ 


\section{Cureus}

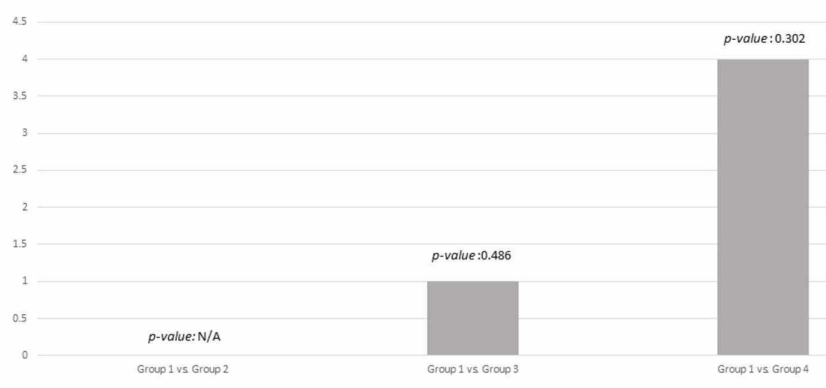

FIGURE 2: Primary endpoint using a brain natriuretic peptide (BNP) cutoff of $54 \mathrm{pg} / \mathrm{mL}$

The Fisher's exact test using BNP and TnT as continuous variables determined that only BNP is the statistically significant predictor for mortality among patients with obesity Grade 3 admitted for acute PE (Table 2).

\begin{tabular}{|c|c|c|}
\hline Variables & OR (95\% Cl) & $p$-value \\
\hline Age $\geq 55$ & $3.57(0.38,33.20)$ & 0.3709 \\
\hline Gender, F vs $M$ & $2(0.21,18.7)$ & 1.000 \\
\hline BNP & $1.003(1.001,1.005)$ & 0.0022 \\
\hline Maximum TnT & $0.92(0.57,1.68)$ & 0.6848 \\
\hline $\mathrm{CHF}$ & $3.93(0.61,25.04)$ & 0.148 \\
\hline COPD & $1.06(1.00,1.12)$ & 1.00 \\
\hline Renal failure & $3.93(0.619,25.04)$ & 0.148 \\
\hline CAD & $2.46(0.24,24.84)$ & 0.4096 \\
\hline Malignancy & $1.92(0.195,18.97)$ & 0.479 \\
\hline
\end{tabular}

\section{TABLE 2: Logistic regression of variables}

BNP: Brain natriuretic peptide; TnT: Troponin T; CHF: Congestive heart failure; COPD: Chronic obstructive pulmonary disease; CAD: Coronary artery disease.

Receiver operating characteristic (ROC) analysis (Figure 3) identified that a level of 684 (sensitivity of 60\%, specificity of $93.1 \%$ ) is the cutoff level to predict mortality in the population studied. 


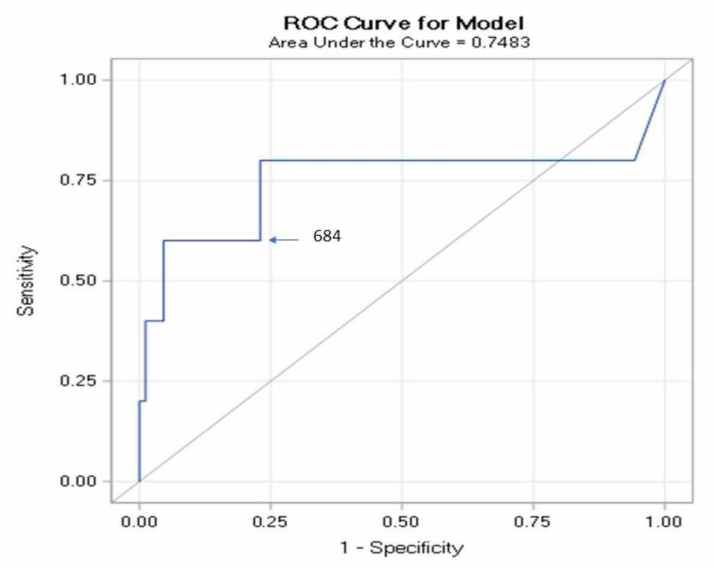

FIGURE 3: ROC analysis

\section{Discussion}

Obesity is increasing considerably worldwide. Based on an average prevalence of obesity of $35.7 \%$ [6], the incidence of venous thromboembolism of 1.92/1000 cases [2] and a likelihood of venous thromboembolism (VTE) among obese population almost twice that of persons without obesity (OR of 1.84 (95\% CI, 1.55-2.18)) [7], we estimated that between 2009-2010, in a population with ages between 45 and 79, like ours, the incidence of VTE was $2.7 / 1000$ cases. In the general population, $60 \%$ of all VTE occurs in people aged 70 or older, but patients with obesity Grade 3 have a tendency to experience first pulmonary embolism at a much younger age [8]. The mean age in our study was $55 \mathrm{SD}+/-14$ years, similar to the mean age reported in other studies $57+/-17$ years [9]. According to our demographics, there is a higher risk of PE in Grade 3 obesity women, as determined by others, who recognized that the relative risk of idiopathic PE (defined as subjects without a history of surgery or major trauma in the last month) was as high as 5.79 in individuals with a BMI $\geqslant 35 \mathrm{~kg} / \mathrm{m}^{2}(\mathrm{p}<0.001)[10]$.

Hemodynamic instability, defined as SBP $<90 \mathrm{mmHg}$ for at least 15 minutes, is a critical determinant of prognosis and the main clinical indicator to administer the definitive treatment represented by systemic or catheter-based thrombolysis or thrombectomy. Hemodynamic instability was documented in $15.2 \%$ of cases, with the majority recorded among the patients in group 4 . All patients in group 1 (100\%) and $96 \%$ of patients in group 3 had a sustained SBP $\geqslant 90 \mathrm{mmHg}$.

In acute PE, BNP is released due to right ventricular wall distension as a consequence of pressure overload and right ventricular dysfunction (RVD). A recent systematic review and meta-analysis examined the prognostic value of BNP in the general population with PE and concluded that while a high BNP has a positive predictive value of around $14 \%$ (95 CI 11\% to $18 \%$ ), a normal BNP has a negative predictive value (NPV) of 99\% (CI 97\% to 100\%) [11]. Troponin I and T are markers of myocardial injury. According to a recent metanalysis, an increased troponin is correlated with higher mortality, but a negative high sensitivity troponin level provides an NPV of 98\% of prediction a 30-day outcome in the patients with PE [12,13].

The interpretation of both BNP and TnT values in patients with obesity grade 3 is particularly challenging. The majority of our patients (53.2\%) had a BNP $<100 \mathrm{pg} / \mathrm{mL}$. From the data available in patients with HF, one has to consider the potential falsely low results of BNP in at least $20 \%$ of obese subjects [14]. Our assessment confirms that in extremely obese patients, a BNP $<100 \mathrm{pg} / \mathrm{mL}$ is recorded in $20 \%$ of patients with PE, and a coexisting diagnosis of CHF. Up to $66 \%$ of individuals had abnormal $\mathrm{TnT}(\geqslant 0.03)$, but only $8.6 \%$ of patients had known CAD. The potential major confounding factor in the troponin interpretation is renal failure, which was present in $36 \%$ of patients with abnormal TnT.

Our study's primary focus was the association between combined normal BNP and normal troponin (Group 1) and mortality at 30 days. All patients in group 1 remained hemodynamically stable throughout the hospitalization. None of them had RVD as defined by CTA (RV diameter/left ventricular diameter ratio of $\geqslant 1$ in conjunction with septal bowing). The imaging was reviewed independently by two radiologists. Although the NPV of these tests is $98.8 \%$, we were not able to detect a statistically significant difference between group 1 and the other groups in predicting mortality at 30 days. Using a BMI-related BNP cutoff level of 54 $\mathrm{pg} / \mathrm{mL}$, recommended by the Breathing Not Properly trial, no additional benefit was noted [15]. The most likely reason for these results was the reduced incidence of all-cause mortality within 30 days (5.43\%), which is much lower than previously reported, likely owing to the immediate reperfusion strategies employed in 
these cases and much younger age than the general population with PE [2]. Either systemic or catheter-based thrombolysis in our study was administered in $9.75 \%$ of cases, which is much higher than the number of patients in the general population that benefit from thrombolysis $(1.9 \%-4.2 \%)[16,17]$.

The logistic regression analysis, using BNP and troponin as continuous variables, isolated BNP as an independent predictor of mortality at 30 days. ROC analysis determined that a level of 684 is the cutoff level to predict mortality in the population studied. We consider different hypotheses to explain this result. One of the reasons could be that BNP is higher in women, and our population included women predominantly; however, the logistic regression indicated that there was no significant consequence of gender on the risk of mortality. The other potential explanation would be that BNP is a nonspecific biochemical marker that indicates multiple risk factors that reflect ventricular dysfunction [18]. Few reports that compared BNP and troponin in the risk stratification of PE in the general population reached a similar conclusion [19-20]. The absence of association between elevated troponins and outcome is partly due to the low 30-day mortality and the possibility that troponins are frequently abnormal among patients with Grade 3 obesity [5].

Our report included a larger number of patients, but the low rate of all-cause mortality events at 30 days and the retrospective nature of our study make it very difficult to draw further conclusions as to the other associated risk factors.

There are a few more observations that we learned from reviewing the data. In our study, a definitive treatment, such as either systemic or catheter-based thrombolysis, was administered in $9.75 \%$ of cases, a much higher figure than the number of patients in the general population that benefit from thrombolysis (1.9\% - 4.2\%) [16,17]. The main concern following the administration of thrombolytics is significant bleeding, defined by prior studies as intracranial bleed or major bleed requiring transfusions within one week of treatment [21]. In our study, the survival rate was 100\% within 30 days with no significant bleeding recorded between treatment and day 14 . The presence of comorbidities were higher (47.8\%) than in similar studies of non-severely obese subjects, which agrees with the prior observation that advanced age and not the comorbidities is the most important determinant of the bleeding complication related to thrombolysis $[22]$.

\section{Conclusions}

The study provided the opportunity to appreciate a more frequent use of thrombolysis and a low rate of major complications in patients with PE who have Grade 3 obesity. To our knowledge, this is the first report that examined the biomarkers' behavior in this selected population and estimated the independent predictive value of BNP and troponin but did not include parallel imaging, which is the common practice. The hypothesis that BNP has a higher predictive value than troponin emphasizes the need for prospective validation of the role of the biomarker in the risk stratification in patients with PE and Grade 3 obesity.

\section{Additional Information \\ Disclosures}

Human subjects: Consent was obtained by all participants in this study. Institutional Review Board Assurance \#FWA00020300 260 Ashley Street, 3rd floor Hartford, CT 06105 issued approval Number. IRB\#: SMH-18-05. Number. IRB\#: SMH-18-05 Status: Approved Approval Date: 03/01/2018 Expiration Date: 02/28/2019 Type of Review: Expedited Category (if applicable): Category 5: Research involving materials (data, documents, records, or specimens) that have been collected, or will be collected solely for nonresearch purposes (such as medical treatment or diagnosis) Form of Consent: Waiver of authorization of consent approved 46.116 (d) Subpart Determinations (as applicable): N/A Approved Key Study Personnel: Borz-Baba, Carolina This approval includes the following materials: - Data Collection Sheet - Acute Pulmonary Study Protocol Request for Reapproval/Closure Form: This project requires continued review and approval by the IRB prior to the expiration date. You will be expected to submit your continuing review report at least 6 weeks prior to the expiration date of: 02/28/2019. The approval of the project will be considered "expired" if your "Reapproval/Closure" Form has not been approved prior to that expiration date. An expired study means that any work with human subjects may not be conducted. All research activities must stop including (but not limited to) new enrollment, screening, study visits, medical record review, data analysis, presentations and publications until re-approval has been granted. The "Reapproval/Closure" Form must be completed in its entirety. Protocol and Consent Changes: You are expected to inform the IRB of proposed protocol or informed consent changes. Any such change must be approved by the IRB prior to implementation, except in cases of emergency, when prearranged with the chairman or their designee. To do so, submit the revised materials using the "Protocol Amendment" Form. Unanticipated Problems/Adverse Events: You must also notify the IRB promptly of any events when discovered during the course of research and no later than 5 working days after their occurrence: 1. Unexpected AND related adverse events (on-site or off-site) 2 . The death of a research subject on site 3. Unanticipated problem that is a serious adverse event (on-site or off-site) 4. Any complaint of a participant that indicates an unanticipated risk or which cannot be resolved by the research staff 5 . Any other event or other problems which in the opinion of the principal investigator was (1) previously unforeseen and (2) presents risks to research subjects or others 6 . Any event that requires prompt reporting according to the protocol or the sponsor These should be reported by submitting the "Full Unanticipated Problem and Adverse Event Report Form." Responsibilities: As the 
principal investigator (PI), you are responsible for personally conducting or supervising the conduct of human subjects research and for protecting the rights, safety, and welfare of the subjects enrolled in the research. You are expected to ensure your research is conducted in an ethical manner and in accordance with all federal, state, and local laws and regulations, institutional and policies, and requirements or determinations of the IRB. The Trinity Health Of New England IRB Policies and Procedures are available for your review on our website at: http://www.trinityhealthofne.org/policies-and-procedures Sincerely, Signature applied by Dr Latha Dulipsingh on 03/02/2018 01:57:32 PM EST Latha Dulipsingh, MD, FACP, FACE Chairman Institutional Review Board Trinity Health Of New England Responsibilities of the Research Investigator 1. Research investigators acknowledge and accept their responsibility for protecting the rights and welfare of human research subjects and for complying with all applicable provisions of this Institution's IRB. The Principal Investigator is responsible for the compliance of all co-investigators, student investigators, and research associates with the IRB decisions, conditions, and requirements. 2. Research investigators are responsible for conducting studies in accordance with the protocol. 3. Research investigators are required to complete periodic training in the protection of human subjects, as required by Federal regulations and IRB policy. 4. Research investigators are responsible for obtaining consent and for providing a copy of the IRB-approved and signed informed consent document to each subject at the time of consent. 5. Research investigators are responsible for ensuring that only authorized research staff will conduct the consent process. 6 . Research investigators will promptly report changes in previously approved human subject population or research activities to the IRB. Changes will not be initiated without IRB review and approval, except where necessary to eliminate apparent immediate hazards to the subjects. 7 . Research investigators are responsible for reporting progress of approved research to the IRB, as often as and in the manner prescribed by the IRB, on the basis of risks to subjects, but not less than once per year. 8. Research investigators are responsible for notifying the IRB of any change in financial relationships of any investigators that may result in a conflict of interest that was previously undisclosed. 9. Research investigators will promptly report to the IRB any injuries or other unanticipated problems involving risks to subjects or others no later than 5 working days after their occurrence. 10. Research investigators are responsible for notifying the IRB and providing a final report when a study is closed. 11.Research investigators are responsible for notifying the IRB of any gaps in investigator involvement in a study. 12.Research investigators are responsible for ensuring, whenever necessary, that the trial is properly registered with clinicaltrials.gov. 13. Research studies have the resources necessary to protect human subject participants. 14.Researchers are qualified to conduct the research. 15. Adequate time is allotted for the researchers to conduct and complete the research. There are also an adequate number of qualified staff and adequate facilities. 16.Researchers have access to populations that will allow recruitment of the necessary participants. 17.The researchers are provided with the availability of medical or psychosocial resources that participants may need as a consequence of the research. 18.Researchers will follow good clinical practice guidelines. 19.Researchers must disclose significant financial interests including those of the Researcher, and the Researcher's spouse and dependent children (refer to Investigator Conflicts of Interest in Funded Research policy). Animal subjects: All authors have confirmed that this study did not involve animal subjects or tissue. Conflicts of interest: In compliance with the ICMJE uniform disclosure form, all authors declare the following: Payment/services info: All authors have declared that no financial support was received from any organization for the submitted work. Financial relationships: All authors have declared that they have no financial relationships at present or within the previous three years with any organizations that might have an interest in the submitted work. Other relationships: All authors have declared that there are no other relationships or activities that could appear to have influenced the submitted work.

\section{References}

1. ISTH Steering Committee for World Thrombosis Day: Thrombosis: a major contributor to the global disease burden. J Thromb Haemost. 2014, 12:1580-1590. 10.1111/jth.12698

2. Beckman MG, Hooper WC, Critchley SE, Ortel TL: Venous thromboembolism: a public health concern. Am J Prev Med. 2010, 38:495-501. 10.1016/j.amepre.2009.12.017

3. Hales C, Carroll M, Fryar C, Ogden CL: Prevalence of obesity and severe obesity among adults: United States, 2017-2018. NCHS Data Brief, no 360. CDC. 2020,

4. AlJaroudi W, Halley C, Houghtaling P, et al.: Impact of body mass index on diastolic function in patients with normal left ventricular ejection fraction. Nutr Diabetes. 2012, 2:e39. 10.1038/nutd.2012.14

5. Ndumele C, Coresh J, Lazo M, et al.: Obesity, subclinical myocardial injury, and incident heart failure. JACC Heart Fail. 2014, 2:600-607. 10.1016/j.jchf.2014.05.017

6. Prevalence of obesity in the United States, 2009-2010. (2012). Accessed: May 29, 2020: https://www.cdc.gov/nchs/products/databriefs/db82.htm.

7. Ageno W, Becattini C, Brighton T, Selby R, Kamphuisen PW: Cardiovascular risk factors and venous thromboembolism: a meta-analysis. Circulation. 2008, 117:93-102. 10.1161/CIRCULATIONAHA.107.709204

8. Naess IA, Christiansen SC, Romundstad P, Cannegieter SC, Rosendaal FR, Hammerstrøm J: Incidence and mortality of venous thrombosis: a population-based study. J Thromb Haemost. 2007, 5:692-699. 10.1111/j.1538-7836.2007.02450.x

9. Stein D, Beemath A, Olson R: Obesity as a risk factor in venous thromboembolism . Am J Med. 2005, 118:978980. 10.1016/j.amjmed.2005.03.012

10. Severinsen MT, Kristensen SR, Johnsen SP, Dethlefsen C, Tjønneland A, Overvad K: Anthropometry, body fat, and venous thromboembolism: a Danish follow-up study. Circulation. 2009, 120:1850-1857. 10.1161/CIRCULATIONAHA.109.863241

11. Countance G, Le Page O, Lo T, Hamon M: Prognostic value of brain natriuretic peptide in acute pulmonary 
embolism. Crit Care. 2008, 12:109. 10.1186/cc6996

12. Bajaj A, Saleeb M, Rathor P, Sehgal V, Kabak B, Hosur S: Prognostic value of troponins in acute nonmassive pulmonary embolism: a meta-analysis. Heart Lung. 2015, 44:327-334. 10.1016/j.hrtlng.2015.03.007

13. Lankeit M, Jiménez D, Kostrubiec M, Dellas C, Hasenfuss G, Pruszczyk P, Konstantinides S: Predictive value of the high-sensitivity Troponin $\mathrm{T}$ assay and the simplified pulmonary embolism severity index in hemodynamically stable patients with acute pulmonary embolism: a prospective validation study. Circulation. 2011, 124:2716-2724. 10.1161/CIRCULATIONAHA.111.051177

14. Madamanchi C, Alhosaini H, Sumida A, Runge MS: Obesity and natriuretic peptides, BNP and NT-proBNP: mechanisms and diagnostic implications for heart failure. Int J Cardiol. 2014, 176:611-617. 10.1016/j.ijcard.2014.08.007

15. Daniels LB, Clopton P, Bhalla V, et al.: How obesity affects the cut-points for B-type natriuretic peptide in the diagnosis of acute heart failure: results from the Breathing Not Properly Multinational Study. Am Heart J. 2006, 151:999-1005. 10.1016/j.ahj.2005.10.011

16. Keller K, Hobohm L, Ebner M, Kresoja KP, Münzel T, Konstantinides SV, Lankeit M: Trends in thrombolytic treatment and outcomes of acute pulmonary embolism in Germany. Eur Heart J. 2020, 41:522-529. 10.1093/eurheartj/ehz236

17. Adusumalli S, Geller B, Yang L, Giri J, Groeneveld PW: Trends in catheter-directed thrombolysis and systemic thrombolysis for the treatment of pulmonary embolism. Am Heart J. 2019, 207:83-85. 10.1016/j.ahj.2018.09.013

18. Omland T, Persson A, Ng L, et al.: N-terminal pro-B-type natriuretic peptide and long-term mortality in acute coronary syndromes. Circulation. 2002, 106:2913-2918. 10.1161/01.cir.0000041661.63285.ae

19. Binder L, Pieske B, Olschewski M, Geibel A, Klostermann B, Reiner C, Konstantinides S: N-terminal probrain natriuretic peptide or troponin testing followed by echocardiography for risk stratification of acute pulmonary embolism. Circulation. 2005, 112:1573-1579. 10.1161/CIRCULATIONAHA.105.552216

20. Maziere F, Birolleau S, Medimagh S, Arthaud M, Bennaceur M, Riou B, Ray P: Comparison of troponin I and $\mathrm{N}$-terminal-pro B-type natriuretic peptide for risk stratification in patients with pulmonary embolism. Eur J Emerg Med. 2007, 14:207-211. 10.1097/mej.0b013e3280bef891

21. Meyer G, Vicaut E, Danays T, et al.: Fibrinolysis for patients with intermediate-risk pulmonary embolism . N Engl J Med. 2014, 370:1402-1411. 10.1056/NEJMoa1302097

22. Kostrubiec A, Pruszczyk P, Bochowicz A, et al.: Biomarker-based risk assessment model in acute pulmonary embolism. Eur Heart J. 2005, 26:2166-2172. 10.1093/eurheartj/ehi336 